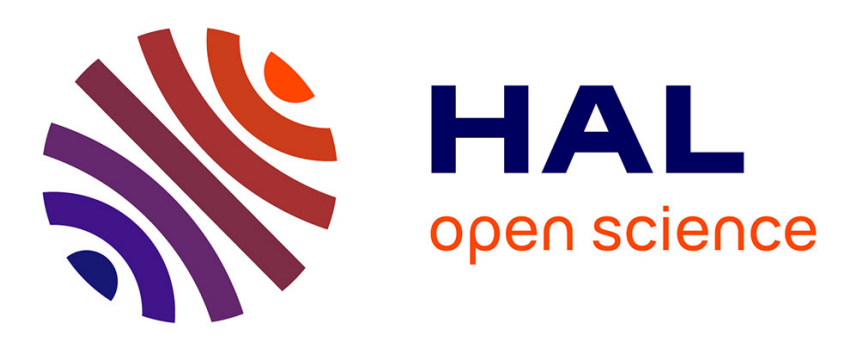

\title{
A Framework for Production System Design: Insights from Industrial Experience
}

Nico J. Vandaele, Catherine J. Decouttere

\section{To cite this version:}

Nico J. Vandaele, Catherine J. Decouttere. A Framework for Production System Design: Insights from Industrial Experience. IFIP International Conference on Advances in Production Management Systems (APMS), Sep 2014, Ajaccio, France. pp.76-82, 10.1007/978-3-662-44733-8_10 . hal-01387150

\section{HAL Id: hal-01387150 \\ https://inria.hal.science/hal-01387150}

Submitted on 25 Oct 2016

HAL is a multi-disciplinary open access archive for the deposit and dissemination of scientific research documents, whether they are published or not. The documents may come from teaching and research institutions in France or abroad, or from public or private research centers.
L'archive ouverte pluridisciplinaire HAL, est destinée au dépôt et à la diffusion de documents scientifiques de niveau recherche, publiés ou non, émanant des établissements d'enseignement et de recherche français ou étrangers, des laboratoires publics ou privés.

\section{(c)(1)}

Distributed under a Creative Commons Attribution| 4.0 International License 


\title{
A Framework for Production System Design: Insights from Industrial Experience
}

\author{
Nico J. Vandaele ${ }^{12}$ and Catherine J. Decouttere ${ }^{1}$ \\ ${ }^{1}$ Katholieke Universiteit Leuven, Faculty of Business and Economics, Naamsestraat 69, 3000 \\ Leuven, \\ ${ }^{2}$ KULAK, E. Sabbelaan 53, 8500 Kortrijk, \\ Nico.Vandaele@kuleuven.be \\ Catherine. Decouttereakuleuven.be
}

\begin{abstract}
In this paper we want to share our findings from our industrial experience in the field of system design, more precisely in production system design. We start by the observation that many rigorous designs of production systems are not facing the implementation success they suggest. We indicate three basic reasons for this: limited stakeholder involvement, lack of out-of-the-box thinking and the dominance of financial and technical evaluation criteria. Based on these findings, we suggest a five step approach: the stakeholder analysis, the definition of key performance indicators, the scenario generation, the scenario ranking and the scenario implementation.
\end{abstract}

Keywords. Scenario generation, production system design, multi-criteria evaluation, stakeholder analysis.

\section{Introduction}

If it comes to radical changes of production systems in the light of global-local considerations, the design of new production systems has to be much more far reaching than currently practiced. This is because the production systems of the future have to respond to the needs of many different stakeholders, which are often conflictive in their performance evaluation of the new production system $[7,10]$. The literature is teeming of rigorous papers, which model and optimize production systems [11]. However, much too often these extremely promising designs are not implemented as they are reported and many of these designs are abandoned before they are able to prove their full potential. The question raises: "What is the reason for this?" Since decades we make use of the best modelling approaches, optimizing methodologies and computer power [16]. Based on our experience from different modelling and implementation projects [15], we believe that there are several reasons for this, ranging from a limited stakeholders' involvement, over a lack of out-of-the-box thinking towards a missing link between quantitative and qualitative approaches towards production system design. In order to counteract these observations, contemporary pro- 
duction system design should build upon knowledge generated both inside as well as outside the current as-is production system.

The contribution of this paper is three-fold: (1) we embrace the modelling of production systems with a stakeholder perspective; (2) we extend the construction, evaluation and ranking of the different production system design scenarios to include value based performance measures and (3) we use the outcomes of analytical models of production systems in a multi-criteria ranking methodology.

Section 2 explores the reasons of weak implementation of developed production system models. Section 3 proposes a five step framework to counteract these findings. We conclude, including examples, in section 4.

\section{Reasons for implementation difficulties and a glance at their countermeasures}

Limited stakeholders' involvement. All too often new systems are designed upon the request of a single or a limited set of stakeholders [4]. At first sight, this makes the production system design process efficient as the concerns of only a few stakeholders are not that difficult to grasp and are most likely not conflicting due to their one-sided origin. The required performance measures are defined in a short notice and the number of elective scenario's fulfilling these performance measures is usually rather small. Therefore, often financial or technological performance measures suffice as the stakeholders' origin is internal to the organization whereto the production system belongs. In the same atmosphere, the goal of the new production system often boils down to a single performance measure, mostly a financial one under which technological issues are covered. As a consequence, optimization can be used effectively to further specify the optimal parameter settings of the design scenario [8]. This optimal design scenario is ready for implementation. However, as soon as this scenario is facing practical circumstances and considerations put forward by stakeholders belonging to the environment into which the production system is implemented, the scenario will suffer and will most likely be prohibited to deliver its expected performance. Even if the optimal design scenario is not left aside, it will definitely be amended to accommodate the environmental criticism [15]. These undesirable effects and amendment efforts could have been avoided if a critical number of stakeholders would have been incorporated earlier in the design process [9]. Later in this paper we will preserve the involvement of all important stakeholders via a stakeholders' analysis in order to list up all relevant key performance indicators (KPI's).

Lack of out-of-the-box design options. The composition of new radical design scenarios is a function of the different ways of thinking that are involved in the scenario building process. If only a small number of stakeholders is considered, there is a great chance that the new designs are close to the as-is system, leading to incremental scenario's with either marginal improvements or with significant, but onedimensional improvements. Building upon our experience for instance in health care system design [15], it became clear that taking into account a variety of relevant stakeholders increases both the number as well as the diversity of the design 
scenarios. This offers a big chance to open up new ways of operation and performance possibilities. New building blocks for the production system are brought to the design table in order to serve the outlined set of KPI's. As a consequence, these different stakeholders with their diverse performance criteria turn the single optimization problem outlined above into a multi-objective evaluation, as can be seen in Table 1.

\begin{tabular}{l|l|l}
\multicolumn{3}{c}{ Multi-KPI Evaluation } \\
\hline \multicolumn{1}{c|}{ Technology } & \multicolumn{1}{c}{ Economies } & \multicolumn{1}{c}{ Human Values } \\
\hline Flow & Profit & Safety \\
Skills & Investments & Fairness \\
Process complexity & Operating cost & Ecological footprint \\
Product Quality & Time to market & Motivation
\end{tabular}

Table 1. A balanced evaluation of a production system: technology, economies and values.

This is an adapted version of a figure reported earlier in literature [13]. The key issue is that all important KPI's are listed and that a praticular balance is preserved between technological, economical and value based KPI's in order to keep all stakeholders engaged. This is crucial for the succes of the implementation process.

The dominance of quantitative financial and technological KPI's. If different scenario's are to be assessed with respect to a complex set of KPI's a lot of qualitative aspects come into the picture. It is very tempting to either neglect the qualitative aspects like value based performance indicators in favour of more quantitative metrics of a technological or economic nature [14]. This poses a problem as some of the less tangible KPI's are nevertheless linked to important stakeholders. For instance, customer perceived value serves as a commonly used KPI for the stakeholders from the external demand side of a production system [15]. At this point, we strongly support the inclusion of KPI's which try to measure qualitative aspects of the KPI set if no straight quantitative metrics are available. As a consequence, we end up with a multicriteria evaluation of the production system scenarios which makes the use of a ranking method mandatory. Although different ranking methods are presented in literature [13], we really do want to avoid the use of weighting scoring models. The advantage seems to be that this brings us back to a single objective function (like utility functions), which is beneficial for optimization purposes. However, it shifts the discussion away from the relevance of the criteria itself towards a discussion related to the weights of the different criteria. This is no step forward. Instead, we opt for a nonparametric ranking method, as we will explain later in the sequel of this paper.

\section{A Framework}

In this section we propose a framework which boils down to a five step approach. This framework has been initially developed through our research in R\&D portfolio 
management where a model based decision support approach has been proposed and applied for assessing, ranking and selection within an R\&D portfolio context [14]. The basic reason within $R \& D$ portfolio management is that when it comes to the ranking of $\mathrm{R} \& \mathrm{D}$ projects, the value based dimensions are often very hard to incorporate next to the typical financial or cost based objective functions and their corresponding technological constraints. We proposed a non-parametric approach, where value based measures can be included in the overall assessment, ranking and selection of projects in the portfolio [13]. This framework is currently being elaborated and refined in order to be useful for supply chain design contexts. This paper deals with the application into a production system context.

\subsection{Stakeholder analysis and production system definition}

The stakeholders involved in a production system design effort can be categorized using a two-fold dichotomy: one dichotomy relates to the focus of the stakeholders and deals with the fact that the stakeholder is part of the supply or demand side of the production system. The other dichotomy describes the origin of the stakeholder: either internal or external to the production system. Together with some examples, this can be seen in Table 2 .

\begin{tabular}{|c|c|c|c|}
\hline & & \multicolumn{2}{|c|}{ Focus } \\
\hline & & Supply & Demand \\
\hline \multirow{2}{*}{$\cdot \stackrel{\sigma 0}{\sigma 0}$} & Internal & $\begin{array}{l}\text { Shareholder } \\
\text { Employee } \\
\text { Manager }\end{array}$ & $\begin{array}{l}\text { User } \\
\text { Customer } \\
\text { Intermediary }\end{array}$ \\
\hline & External & $\begin{array}{l}\text { Regulatory body } \\
\text { Supply Chain Partners } \\
\text { Institutional body }\end{array}$ & $\begin{array}{l}\text { Government } \\
\text { Public opinion } \\
\text { Society at large }\end{array}$ \\
\hline
\end{tabular}

Table 1. The two-fold stakeholders' dichotomy

From the supply and demand point of view, the production system is defined as a collection of resources organized together in order to serve a particular set of flows as visualized in Fig 1. This is the traditional viewpoint from an analytical modelling perspective: resources are part of the supply side of the production system and flows originate outside the production system in the environment, are processed through the resources of the production system in a number of steps and at the end leave the system again to re-join the environment. We define the set of resources and their relationships as the supply side of the production system. Examples of important stakeholders are definitely the shareholders, employees and managers in general. In most analytic models, the demand side is assumed to be exogenous: the origin and the characterization of flows lies outside the production system. However, this supply side contains considerable opportunities in terms of stakeholder analysis as there are: the customers, users, intermediaries, ...[5]. Opportunities can be found for instance in different flows serving different market segments, various evolutions through time 
(both in mix changes and product/service flow portfolio changes), geographical evolutions, etc. All of these demand side opportunities may eventually turn into different scenarios as will be discussed in section 3.3 of this paper. This concludes the internal supply and demand view of the production system.

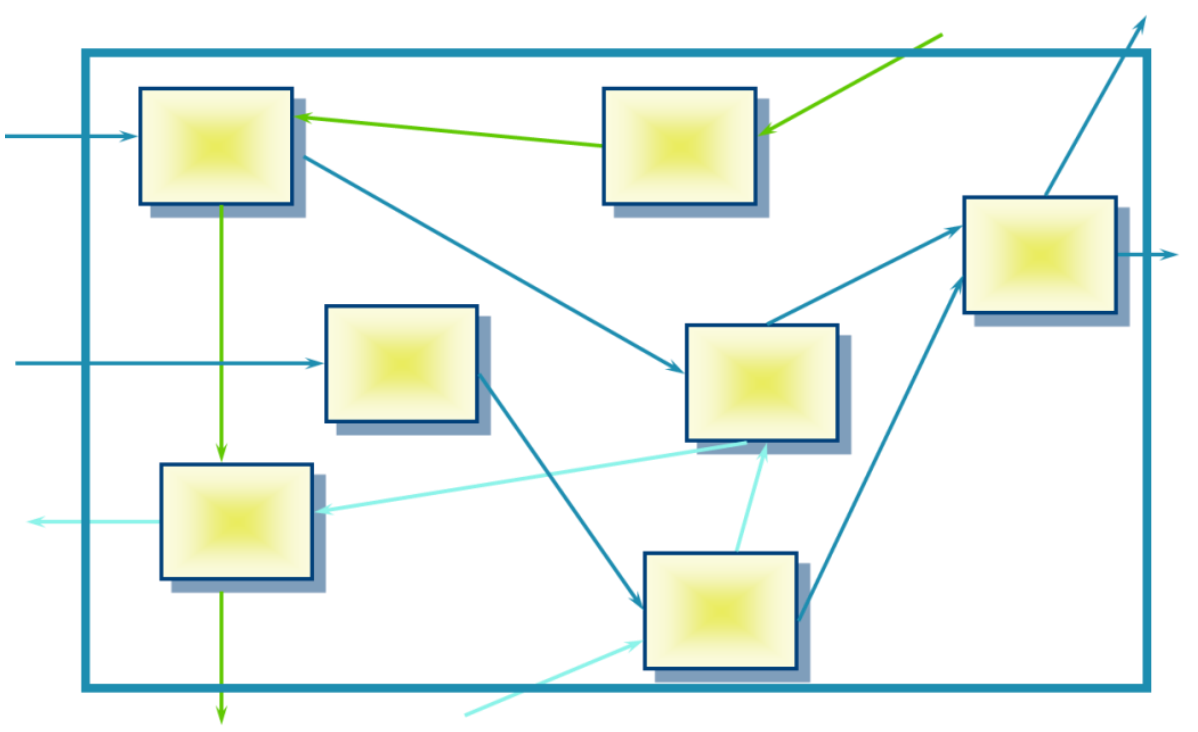

Fig. 1. The production system as a flow system

If it comes to an in-depth stakeholder analysis [6], other important external stakeholders can be located in the system's environment. On the supply side various supply chain partners, regulatory bodies, institutional bodies and the like are further shaping the stakeholders' group. On the demand side, more remote stakeholders are located in the public opinion, in the social media or the community at large, for instance the incorporation of sustainability in production systems. Also ethical and social aspects like working conditions, general welfare of human beings and the environmental concerns are examples of external stakeholders' perspectives on the demand side.

\subsection{Production system KPI's and requirements}

If these stakeholders' viewpoints are relevant they must be reflected in the KPI set to evaluate the production system design scenarios. Revealing these KPI's is not always trivial and enough effort has to be devoted to gathering the stakeholders' views and the detection of the KPI's they are standing for [1]. Mostly, stakeholders also bear thresholds in their minds, against which the production system design scenario will be put. This can later on be used in the next step as a criterion to allow a scenario to be part of the long list of feasible and acceptable scenarios. This typical iterative process ends with a KPI set which is a specific instance of the general statement in Fig 1. Without going into detail, we want to stress the importance of finding appropriate metrics for these KPI's. These metrics should be robust, clearly defined and numeri- 
cal. The latter includes scaled metrics which are typically used for measuring the more intangible KPI's.

\subsection{Scenario generation and validation}

From the stakeholders' opinions and their derived KPI's, building blocks for the production system will emerge. Both existing and new building blocks will be combined into different scenarios. At this point the traditional analytical modelling comes into the picture and contributes its inherent value: every scenario needs to be modelled as rigorously as possible in order to get the best parameter setting for a given scenario $[2,3]$. If particular aspects can be optimized, this should be done [12]. Subsequently, every scenario modelled will be assessed against the complete set of KPI's outlined in the previous step, which is a broader set than the KPI's delivered by the analytical model only. As this KPI set eventually contains thresholds induced by particular stakeholders, a scenario not passing the thresholds can be left aside in this phase. So the output of this phase is a long list of feasible scenarios endorsed by the stakeholders through their KPI's and potential thresholds.

\subsection{Ranking of production system scenarios}

This phase relies on a decision support model for scenario ranking. The long list of feasible scenarios is ranked according to the multi-criteria performance defined by the set of KPI's. Many methodologies can be put forward. We rely on Data Envelopment Analysis (DEA), which is a non-parametric ranking procedure. At this point, we can build upon our experience in the R\&D portfolio management area where DEA has been applied successfully to rank the various design alternatives in the development of new products and services [14]. The major difference with production systems is that in an R\&D context, the help of analytic flow models like we used in the previous step for the design of production systems is not available. In the production system design context, the existence of an analytical model should be exploited.

\subsection{Production system scenario selection and implementation}

One of the consequences of using a non-parametric method for multi-criteria scenario ranking is the occurrence of multiple 'best' scenarios, called peers. From a practical point of view this is quite natural and for the decision support the segregation between the peers and the other scenario's is important and very useful. The final decision board will be exposed to this set of peers. Very often, if one scenario is finally chosen for implementation, the set of peers contains useful scenarios to construct fall back plans if the dynamics of the environment change the setting for the scenario chosen and implemented. 


\section{Conclusions and further research}

In this paper we reflected on production system design based on our experience in industry. It turned out that rigorous modelling is not always sufficient to reach successful implementations. In an attempt to counteract these effects, we suggest a five step approach, including stakeholder analysis and definition of a set of key performance indicators, scenario generation and scenario ranking leading to the implementation a stakeholder bought-in production system design.

Future research challenges include the quest for more refined KPI metrics and the development of an adequate visualization for better insight and decision making in the various steps.

Acknowledgments. This research has been supported by the GSK Research Chair.

\section{References.}

1. Beyan, O. D. and Baykal, N. (2012). A knowledge based search tool for performance measures in health care systems. Journal of medical systems, 36(1):201-221.

2. Brailsford, S. C. (2008). System dynamics: What's in it for healthcare simulation modelers? In Simulation Conference, 2008. WSC 2008. Winter, pages 1478-1483. IEEE.

3. Brailsford, S. C., Lattimer, V., Tarnaras, P., and Turnbull, J. (2004). Emergency and ondemand health care: modelling a large complex system. Journal of the Operational Research Society, 55(1):34-42.

4. Clarkson, P. J., Buckle, P., Coleman, R., Stubbs, D., Ward, J., Jarrett, J., Lane, R., and Bound, J. (2004). Design for patient safety: a review of the effectiveness of design in the UK health service. Journal of Engineering Design, 15(2):123-140.

5. Donaldson, K., Ishii, K., and Sheppard, S. (2006). Customer value chain analysis. Research in Engineering Design, 16(4):174-183.

6. Elias, A. A., Cavana, R. Y., and Jackson, L. S. (2002). Stakeholder analysis for R\&D project management. $R \& D$ Management, 32(4):301-310.

7. Freeman, R. E. (2010). Strategic management: A stakeholder approach. Cambridge University Press.

8. Lambrecht, M. R. and Vandaele, N. J. (1996). A general approximation for the single product lot sizing model with queueing delays. European Journal of Operational Research, 95(1):73-88.

9. Mitchell, R. K., Agle, B. R., and Wood, D. J. (1997). Toward a theory of stakeholder identification and salience: Defining the principle of who and what really counts. The Academy of Management Review, 22(4):pp. 853-886.

10. Solaimani, S., Guldemond, N., and Bouwman, H. (2013). Dynamic stakeholder interaction analysis: Innovative smart living design cases. Electronic Markets, pages 1-12.

11. Suri, R., J. S. and Kamath, M. (1993). Performance evaluation of production networks, in "Logistics of production and Inventory". Elsevier Science Publishers.

12. Vandaele, N., Nieuwenhuyse, I. V., and Cupers, S. (2003). Optimal grouping for a nuclear magnetic resonance scanner by means of an open queueing model. European Journal of Operational Research, 151(1):181 - 192.

13. Vandaele N., Landrieux B. and Decouttere C., 'The Sustainable Reconciliation between Technological, Financial and People Aspects in R\&D Portfolio Management.', Proceed- 
ings of the $6^{\text {th }}$ IEEE International Conference on Management of Innovation and Technology, 2012, 57-61.

14. Vandaele, N. J. and Decouttere, C. J. (2013). Sustainable R\&D portfolio assessment. Decision Support Systems, 54(4):1521 - 1532.

15. Decouttere C. and Vandaele N., 'A broader view on health care system design and modelling', 2013, KBI Research Report 1323, KU Leuven 37 pp., submitted for publication.

16. Whitt, W. (1983). The queueing network analyzer. The Bell System Technical Journal, 62 (9):2779-2815. 